\title{
Liofilização e avaliação da estabilidade da polpa de manga 'Ataulfo'
}

\author{
Lyophilization and evaluation of the stability of 'Ataulfo' mango pulp \\ Liofilización y evaluación de la estabilidad de la pulpa de mango 'Ataulfo'
}

Recebido: 05/03/2021 | Revisado: 11/03/2021 | Aceito: 15/03/2021 | Publicado: 22/03/2021

\author{
Marylia Sousa Costa \\ ORCID: https://orcid.org/0000-0001-9593-4233 \\ Universidade Federal de Campina Grande, Brasil \\ E-mail: marylia.sousacosta@gmail.com \\ Acácio Figueiredo Neto \\ ORCID: https://orcid.org/0000-0002-0326-9123 \\ Universidade Federal do Vale do São Francisco, Brasil \\ E-mail: figueiredoacacio@gmail.com \\ Josivanda Palmeira Gomes \\ ORCID: https://orcid.org/0000-0002-2047-986X \\ Universidade Federal de Campina Grande, Brasil \\ E-mail: josivanda@gmail.com \\ Josenara Daiane de Souza Costa \\ ORCID: http://orcid.org/0000-0002-8706-7405 \\ Instituto Federal de Educação, Ciência e Tecnologia do Piauí, Brasil \\ E-mail: josenara.costa@gmail.com \\ Vivianni Marques Leite dos Santos \\ ORCID: http://orcid.org/0000-0001-8741-8888 \\ Universidade Federal do Vale do São Francisco, Brasil \\ E-mail: vivianni.santos@gmail.com \\ Bruno Emanuel Souza Coelho \\ ORCID: https://orcid.org/000-0002-4526-6369 \\ Universidade Federal do Vale do São Francisco, Brasil \\ E-mail: souza.coelho18@gmail.com
}

\begin{abstract}
Resumo
Com o intuito de desenvolver um produto de alta durabilidade e que não tenham alterações de suas características físico-químicas, nutricionais e sensoriais, objetivou-se com este trabalho estudar a produção de pós liofilizados a partir da manga da variedade 'Ataulfo' em três diferentes estádios de maturação ( 2,3 e 4), bem como seu armazenamento em dois tipos de embalagens seguidas das análises de suas características físicas e físico-químicas. Os pós foram armazenados em duas embalagens uma laminada e outra de polietileno e seu armazenamento em temperatura ambiente, teve duração de 180 dias e a cada 30 dias eram feitas análises quanto a atividade de água (aw), umidade, cor $\left(\mathrm{L}^{*}, \mathrm{a}^{*} \mathrm{e} \mathrm{b}^{*}\right)$, vitamina $\mathrm{c}$, sólidos solúveis $\left(\mathrm{Brix}^{\circ}\right)$ e a acidez total titulável (ATT). Os resultados foram tabulados com o auxílio do software Assistat, e o delineamento utilizado foi inteiramente casualizado em esquema fatorial utilizando o teste de Tukey a 5\% de probabilidade e análise de regressão. Com base nos resultados observouse diferenças físicas e físico-químicas dos pós de polpa da manga 'Ataulfo' nos três diferentes estádios de maturação; que a liofilização é um processo de secagem eficiente e eficaz na desidratação da polpa de manga; e principalmente que a embalagem laminada funcionou durante todo o período de armazenamento como uma barreira promovendo a melhor preservação de um modo geral das propriedades físico-químicas dos pós.
\end{abstract}

Palavras-chave: Mangifera indica; Desidratação; Estágios de maturação.

\begin{abstract}
In order to develop a product of high durability and that do not have changes in its physical-chemical, nutritional and sensory characteristics, the objective of this work was to study the production of lyophilized powders from the 'Ataulfo' mango in three different maturation stages $(2,3$ and 4), as well as its storage in two types of packaging followed by analysis of their physical and physical-chemical characteristics. The powders were stored in two packages, one laminated and the other made of polyethylene. at room temperature, it lasted 180 days and every 30 days, analyzes were made for water activity (aw), humidity, color $\left(L^{*}, a *\right.$ and $\left.b *\right)$, vitamin c, soluble solids (Brix ${ }^{\circ}$ ) and titratable total acidity (ATT). The results were tabulated with the assistance of the Assistat software, and the design used was entirely randomized in a factorial scheme using the test. Tukey's at $5 \%$ probability and regression analysis. Based on the results, physical and physical-chemical differences of the 'Ataulfo' mango pulp powders were observed in the three different maturation stages; whereas freeze-drying is an efficient and effective drying process for dehydrating mango pulp; and mainly that the laminated packaging worked throughout the storage period as a barrier promoting the best preservation in general of the physicochemical properties of the powders.
\end{abstract}


Keywords: Mangifera indica; Dehydration; Maturation stages.

\section{Resumen}

Con el fin de desarrollar un producto de alta durabilidad y que no tenga alteraciones en sus características físicoquímicas, nutricionales y sensoriales, el objetivo era para estudiar la producción de polvos liofilizados a partir del mango de la variedad 'Ataulfo' en tres etapas de maduración diferentes (2, 3 y 4), así como su almacenamiento en dos tipos de envases seguidos del análisis de sus características físicas y fisicoquímicas. Los polvos se almacenaron en dos paquetes, uno laminado y otro de polietileno, y su almacenamiento a temperatura ambiente, duró 180 días y cada 30 días se realizaron análisis de actividad de agua (aw), humedad, color $(\mathrm{L} *, \mathrm{a} * \mathrm{yb} *$ ), vitamina c, sólidos solubles (Brix ${ }^{\circ}$ ) y acidez total titulable (ATT). Los resultados se tabularon con la ayuda del software Assistat, y el diseño utilizado fue completamente aleatorizado en un esquema factorial utilizando la prueba Tukey's al 5\% de probabilidad y análisis de regresión. Con base en los resultados, se observaron diferencias físico-químicas de los polvos de pulpa de mango 'Ataulfo' en los tres diferentes etapas de maduración; Considerando que la liofilización es un proceso de secado eficaz y eficaz para deshidratar la pulpa de mango; y principalmente que el embalaje laminado funcionó durante todo el período de almacenamiento como barrera que favorece la mejor conservación en general de las propiedades fisicoquímicas de los polvos.

Palabras clave: Mangifera indica; Deshidratación; Etapas de maduración.

\section{Introdução}

A mangueira (Mangifera indica L.) pertence à família Anacardiaceae, é originária da Índia, é uma fruteira tropical, e seus frutos são climatéricos, sendo apreciado em todo o mundo devido ao seu sabor, aroma e cor agradáveis, apresentando grande importância econômica no mundo todo (Sing et al., 2013; Zotarelli et al, 2017).

O Brasil é sétimo maior produtor e o quarto maior exportador de mangas do mundo, em 2017, a produtividade média foi em torno de 16,87 t/há, sendo o Sudeste e o Nordestem os estados com maior produtividade de manga, sendo o Submédio do Vale do São Francisco, o maior produtor e exportador de mangas in natura, onde responde por $85 \%$ das exportações brasileiras manga frescas, com produtividade média anual de 40 t/ha (IBGE, 2019).

A variedade Ataulfo, que é de origem mexicana, compõe a mangicultura brasileira (Lawson et al., 2019). Introduzida no Vale do São Francisco, a manga 'Ataulfo' se destaca das demais, por apresentar: sabor doce, baixa acidez, aroma intenso, textura cremosa, semente pequena, baixo teor de fibras, sendo bem aceita e muito procurada pelos consumidores (Jahurul al., 2015; Quirós-sauceda et al., 2019).

Apesar da importância econômica e destaque do Brasil na produção mundial de mangas, o Brasil apresenta uma das maiores taxas de perdas pós-colheita de manga, devendo-se aos frutos que são descartados por não apresentarem padrão de qualidade para a exportação do fruto in natura, e do elevado padrão respiratório, que induz a perca de reservas e diminui a qualidade do fruto (Silva et al., 2017).

Como alternativa para o aproveitamento de excedente da produção de mangas, uma das formas de aumentar a estabilidade e conservar os frutos, têm se a secagem, que reduz o teor de água no produto final, reduzindo a deterioração, através da redução da a atividade microbiana e bioquímica dos frutos, além de reduzir custos no armazenamento e transporte (Ochoa-martínez et al., 2012).

O processo de secagem por meio da liofilização, ocorre sob condições de baixas pressões e temperatura controladas, removendo a água do fruto por sublimação, e as vantagens desse processo de secagem em relação aos demais, destaca-se a manutenção das propriedades químicas e sensoriais, o que favorece a aceitação do produto por parte do consumidor, por gerar semelhança às características sensoriais do fruto in natura (Zhao et al., 2015).

Em função da grande aceitabilidade dos consumidores, e da grande comercialização no mercado interno e externo da manga 'Ataulfo', e de suas características fisiológicas, a industrialização por meio da liofilização é uma alternativa eficaz para o seu aproveitamento, agregando valor ao produto, além disso tem como vantagem a conveniência em vários aspectos, entre eles, o consumo e distribuição (Ancos et al., 2018). 
Ademais, a polpa na forma de pó pode ser utilizada como matéria-prima para a produção de diversos produtos, podendo ser comercializada em larga escala, aumentando seu consumo, já que não pode ser prolongado quando se encontra em estado integral (Blancas-Benitez et al., 2015).

Dessa forma, o objetivo deste trabalho foi avaliar a secagem da polpa de manga Cv. Ataulfo, para obtenção da polpa em pó, utilizando frutos em diferentes estádios de maturação, e avaliar a estabilidade através do comportamento do produto armazenado em embalagens de polipropileno e laminada.

\section{Metodologia}

As mangas da variedade 'Ataulfo' foram doadas pela fazenda CS Líder Agrícola, localizada no Vale do São Francisco, mais precisamente no município de Sento Sé - BA.

Os frutos foram separados em três diferentes estádios de maturação ( 2,3 e 4$)$ e selecionados em cada estádio quanto a presença de injúrias mecânicas, ataques fúngicos, insetos e outros defeitos (Figura 1), deixando-os em lotes bem uniformes.

Figura 1. Seleção e homogeneização dos estádios de maturação da manga 'Ataulfo'

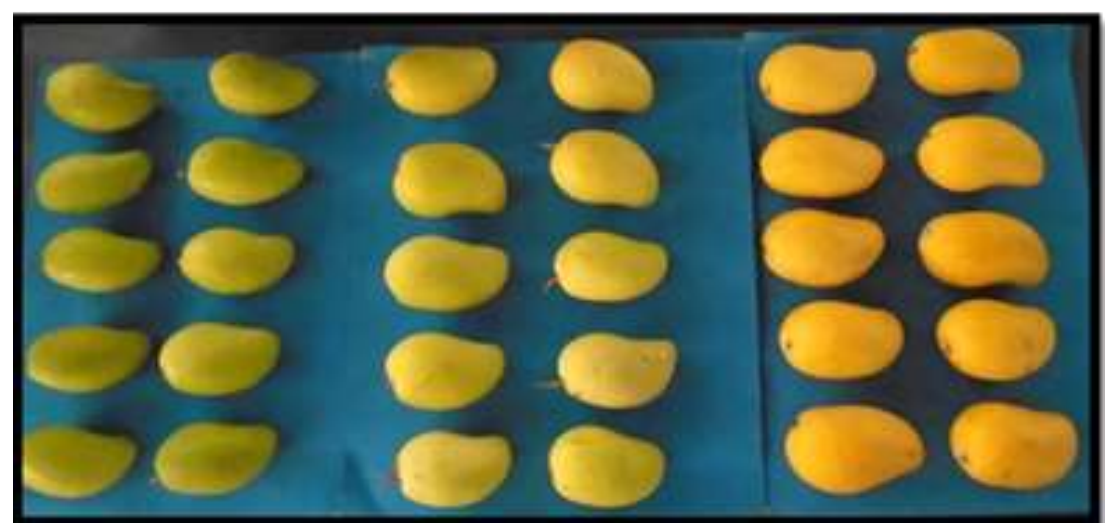

Fonte: Autores.

Em seguida os mesmos foram lavados em água corrente para a retirada das impurezas físicas, sanitizados com solução de hipoclorito de sódio á 100 ppm por 15 minutos, enxaguados para a retirada do excesso de cloro, e secos com papel toalha.

\section{Liofilização da manga 'Ataulfo'}

Os frutos foram descascados, branqueados em água corrente à $70^{\circ} \mathrm{C}$ por um minuto e em seguida submetidos a um choque térmico em água corrente a $15^{\circ} \mathrm{C}$ por um minuto, a fim de para inibir o escurecimento enzimático.

Em seguida as polpas foram processadas e congeladas em bandejas (inox) em camadas finas $(0,5 \mathrm{~cm})$ e dispostas em ultrafreezer a $-50{ }^{\circ} \mathrm{C}$, durante $24 \mathrm{~h}$. As amostras foram dispostas na torre do liofilizador, modelo LS 3000 da marca Terroni, acoplado a bomba de vácuo durante 48 horas até pressão final de $35 \mu \mathrm{mHg}$. Após o término da liofilização foram feitas compressões nas amostras com auxílio de almofariz e pistilo até que as mesmas adquirissem aspecto de pó.

\section{Armazenamento das amostras de manga 'Ataulfo' liofilizadas}

As amostras foram acondicionadas em dois diferentes tipos de embalagens plásticas uma do tipo Stand- up Pouch (laminada) e outra de polietileno, sendo armazenadas por um período de seis meses (180 dias) sob temperatura ambiente, e a cada trinta dias eram feitas análises químicas. Foram analisadas de forma quantitativa por utilizar medições de grandezas 
durante o armazenamento do produto obtido (Pereira et al., 2018). O enfoque matemático foi importante para prever os acontecimentos durante as análises, e a aplicação de um método estatístico possibilitou a segurança dos resultados.

\section{Avaliação da qualidade das amostras de manga 'Ataulfo' liofilizada}

As variáveis químicas avaliadas como parâmetros de qualidade foram: Atividade de água (Aw) foi determinada na temperatura de $25^{\circ} \mathrm{C}$, através de leitura direta em medidor portátil, PawKit, fabricado por Decagon; umidade foi determinada por gravimetria, através da leitura direta à $25^{\circ} \mathrm{C}$, em balança determinadora de Umidade modelo MOC 63; A cor foi aferida por leitura direta, utilizando-se um colorímetro digital portátil da marca Konica Minolta CR 10, com sistema de cor Cielab, sendo obtidos os parâmetros L, que indica luminosidade ou brilho e varia do claro (branco; 100) para o escuro (0:escuro/opaco); a, que indica a cromaticidade no eixo de cor verde(-) para vermelha (+); b, que indica a cromaticidade no eixo da cor azul (-) para amarela (+); O pH (potencial hidrogeniônico) foi determinado por potenciometria, utilizando um pHâmetro digital de bancada com precisão de 0,01 previamente calibrado com soluções tampão de pH 4,0 e 7,0 com os resultados expressos em unidades de $\mathrm{pH}$; a acidez total titulável foi determinada por volumetria ácido-base, empregando a solução alcalina de hidróxido de sódio a 0,01 mol.L $\mathrm{L}^{-1}$ como agente titulante, e a solução alcoólica de fenolftaleína como indicador, expressando os dados em percentual de ácido cítrico; e o teor de sólidos solúveis ( ${ }^{\circ}$ Brix) em água foi determinado utilizando um refratômetro digital, colocando sobre o prisma 1 gota da amostra do pó dissolvido em água destilada, cuja diluição foi de $1 \mathrm{~g}$ da amostra para $10 \mathrm{~mL}$ de água destilada. Os procedimentos analíticos foram realizados seguindo as metodologias do Instituto Adolf Lutz (IAL, 2008); teor de vitamina C (ácido ascórbico) foi quantificado através da metodologia de Tillmans, (AOAC, 1980), modificada por Benassi e Antunes (1988), por volumetria de óxido-redução, empregando a solução de 2,6 diclorofenol-indofenol a 0,02\% como agente tutlante e solução de ácido oxálico (1\%).

\section{Análise estatística}

Os dados foram submetidos a Análise de Variância (ANOVA), em esquema fatorial $3 \times 2 \times 7$, sendo três estádios de maturação (2, 3 e 4) das mangas 'Ataulfo' liofilizadas, duas embalagens distintas, e sete tempos de armazenamentos. Foi utilizado teste de regressão e teste de Tukey a 5\% de probabilidade para avaliação dos resultados. O programa utilizado na análise dos dados foi o software Assistat, Versão 7.7 beta (Silva \& Azevedo, 2016).

\section{Resultados e Discussão}

Em análise a Tabela 1, tem-se para todas as interações, a exceção do pH, da luminosidade (L*) e da intensidade de amarelo $\left(b^{*}\right)$, significância estatística para as demais variáveis estudadas. 
Tabela 1. Resumo da análise de variância referente ao estádio de maturação, embalagens e tempo armazenamento dos pós da manga Ataulfo liofilizado.

\begin{tabular}{|c|c|c|c|c|c|}
\hline \multirow{2}{*}{ Fonte de Variação } & \multicolumn{5}{|c|}{ Quadrado Médio } \\
\hline & $\mathrm{a}_{\mathrm{w}}$ & Umidade & SST & ATT & $\mathrm{pH}$ \\
\hline Maturação (F1) & $0,011 * *$ & $7,81 * *$ & $32303,38 * *$ & $1174,24 * *$ & $27,82 * *$ \\
\hline Embalagens (F2) & $2,38 * *$ & $544,21 * *$ & $146,79 * *$ & $3,25 * *$ & $0,009 * *$ \\
\hline Tempo (F3) & $0,13 * *$ & $57,06^{* *}$ & $4,20 * *$ & $0,15^{* *}$ & $0,078 * *$ \\
\hline F1 X F2 & $0,005^{* *}$ & $0,18^{*}$ & $36,72 * *$ & $1,31 * *$ & $0,0006^{\mathrm{ns}}$ \\
\hline F1XF3 & $0,001 * *$ & $0,31 * *$ & $1,26^{* *}$ & $1,23 * *$ & $17,51 * *$ \\
\hline F2 X F3 & $0,07 * *$ & $16,51 * *$ & $4,68 * *$ & $0,63 * *$ & $5,39 * *$ \\
\hline F1 X F2 X F3 & $0,001 * *$ & $0,13 * *$ & $1,19 * *$ & $0,27 * *$ & $6,96 * *$ \\
\hline Resíduo & 0,0001 & 0,037 & 0,293 & 0,006 & 0,0009 \\
\hline \multirow[t]{2}{*}{$\mathrm{CV}(\%)$} & 2,87 & 2,99 & 1,41 & 1,04 & 0,83 \\
\hline & \multicolumn{2}{|c|}{ Vitamina $\mathrm{C}$} & $\mathrm{L}^{*}$ & $a^{*}$ & $\mathrm{~b}^{*}$ \\
\hline Maturação (F1) & \multicolumn{2}{|c|}{$13354,48 * *$} & $4576,58^{* *}$ & $1031,75^{* *}$ & $609,61 * *$ \\
\hline Embalagens (F2) & \multicolumn{2}{|c|}{$876,82 * *$} & $502,40 * *$ & $54,70 * *$ & $18,43^{\text {ns }}$ \\
\hline Tempo (F3) & \multicolumn{2}{|c|}{$142,86^{* *}$} & $136,63 * *$ & $3,25^{* *}$ & $181,03 * *$ \\
\hline $\mathrm{F} 1 \mathrm{X} \mathrm{F} 2$ & \multicolumn{2}{|c|}{$141,22 * *$} & $58,90 * *$ & $4,87 * *$ & $88,14^{*}$ \\
\hline F1XF3 & \multicolumn{2}{|c|}{$39,20 * *$} & $121,39 * *$ & $14,64 * *$ & $39,63^{*}$ \\
\hline F2 X F3 & \multicolumn{2}{|c|}{$52,32 * *$} & $24,30^{\mathrm{ns}}$ & $1,96 * *$ & $25,39^{\text {ns }}$ \\
\hline F1 X F2 X F3 & \multicolumn{2}{|c|}{15,79} & $15,07^{\mathrm{ns}}$ & $1,11 * *$ & $34,19^{\text {ns }}$ \\
\hline Resíduo & \multicolumn{2}{|c|}{0,03} & 11,61 & 0,112 & 20,78 \\
\hline $\mathrm{CV}(\%)$ & \multicolumn{2}{|c|}{0,69} & 4,65 & 2,97 & 10,61 \\
\hline
\end{tabular}

**, * significativo a $1 \%$ e $5 \%$ de probabilidade, respectivamente e ns não significativo, aw= atividade de água; SST= teor de sólidos solúveis; ATT = acidez titulável; $\mathrm{L}=$ luminosidade; $\mathrm{a}=$ intensidade da cor verde/vermelha; $\mathrm{b}=$ intensidade de amarelo nos pós. Fonte: Autores.

É sabido que a embalagem durante todo o processo de produção de qualquer produto exerce um papel muito importante, por proteger e manter a qualidade do produto de fatores externos como a temperatura, a umidade, a luz e até mesmo de danos físicos. Para tanto fez-se necessário o emprego correto da embalagem que retarde ou minimize todo e qualquer tipo de alterações que venha delongar o tempo de vida útil dos produtos (Sousa et al., 2016). No presente trabalho, as amostras mantiveram-se na forma de pó, com pequena aglomeração nos últimos 30 dias de armazenamento, principalmente nas amostras armazenadas na embalagem de polietileno, porém este fato não impediu a realização das análises de estudo quanto a estabilidade dos pós de manga 'Ataulfo' nos três estádios de maturação, quanto a atividade de água (aw), umidade, cor e suas coordenadas $\mathrm{L}^{*}, \mathrm{a}^{*}$ e $\mathrm{b}^{*}$, sólidos solúveis $\left(\mathrm{Brix}^{\circ}\right)$, vitamina $\mathrm{C}, \mathrm{pH}$ e acidez titulável (ATT) durante 180 dias (6 meses) de armazenamento.

O resultado da interação entre os estádios de maturação (E2, E3 e E4) com os dois tipos de embalagem, laminada e polietileno, para a aw estão representados graficamente no Figura 2.A. As letras minúsculas apresentadas na barra para embalagem laminada mostram diferença significativa de 0,22, 0,25 e 0,28 entre os três estádios dos pós armazenados. Para a embalagem de polietileno houve igualdade estatística no teor de aw de 0,54 para a os pós nos estádios 3 e 4 . Porém entre os 
estádios 3 e 4 e o estádio 2 (aw de 0,5) houve diferença significativa da atividade de água para esta embalagem.

Com relação aos estádios de maturação dos pós armazenados em cada uma das embalagens (letras maiúsculas), o pó da manga 'Ataulfo' do estádio 2 armazenado na embalagem laminada e polietileno apresentou diferença significativa entre essas duas embalagens em torno de 0,28 de diferença, resultado este também observados entre estas mesmas embalagens para os estádios 3 e 4 .

A interação estádio de maturação com tempo de armazenamento da Figura 2.B mostra que houve um aumento gradativo da atividade de água para os três pós E2, E3 e E4 durante os seis meses de armazenamento com valores iniciais em torno de 0,22 e 0,37 e 0,38 respectivamente e final de 0,45 para os três pós.

Quanto a interação embalagem e o tempo de armazenamento o gráfico da figura 2.C, mostra que a embalagem laminada conseguiu durante os seis meses manter de forma linear um controle da aw com uma variação de 0,05 , devido ao material que compõe esta mesma embalagem. Diferentemente da embalagem de polietileno que durante esse período mostrou não ser eficiente no controle da aw cujo aumento foi em torno de 0,4 .

Figura 2. Valores médios da atividade de água (aw) do pó de manga 'Ataulfo' para a interação estádio de maturação com tipo de embalagem (A), estádio de maturação com período de armazenamento (B) e tipo de embalagem com período de armazenamento(C).
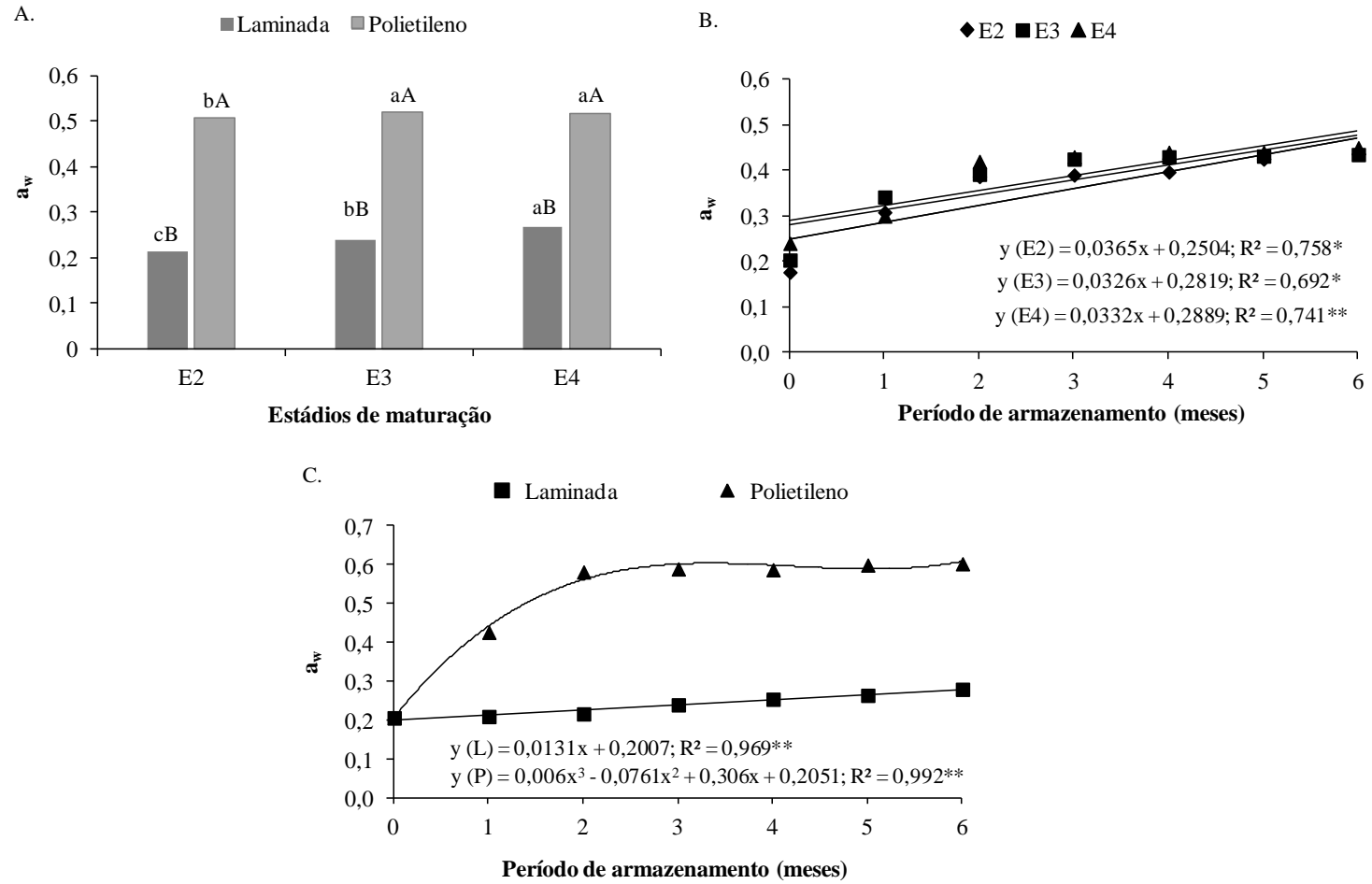

Fonte: Autores.

Costa et al., (2013) observaram para o armazenamento de polpa de maracujá atomizado em embalagem metálica, valores de atividade de água superiores ao presente estudo, e aumento do valor inicial durante os 90 dias de seu armazenamento. Comportamento semelhante foi observado por Galdino et al., (2016) com armazenamento de figo da índia em pó em embalagem também laminada, com aumento da $\mathrm{a}_{\mathrm{w}}$ até o final dos 40 dias de armazenamento. Costa (2017) em estudo de obtenção de polpa de manga em pó pelo processo de liofilização e armazenados em quatro tipos de embalagens por um período de 90 dias percebeu que a embalagem plástica se mostrou uma barreira pouco eficiente quanto ao impedimento do aumento na 
atividade de água na polpa em pó quando comparada com as embalagens laminadas. No entanto, os resultados do presente estudo para a variável atividade de água, a embalagem laminada teve uma maior eficiência mantendo uma $\mathrm{a}_{\mathrm{w}}<0,6$ durante todo o período de armazenamento.

Analisando a interação embalagem com estádio de maturação figura 3.A, verificou-se na embalagem laminada os pós E2 e E3 tiveram uma mesma umidade, em torno de 4\% enquanto que o pó do E4 apresentou uma umidade de $4,5 \%$ para esta embalagem. Na embalagem de polietileno a diferença foi significativa entre os três pós E2, E3 e E4 com teor de umidade de 8,1, 8,4 e 9 respectivamente. Analisando as duas embalagens para um mesmo estádio de maturação do pó houve diferença significativa entre elas para os três estádios. Confirmando que, mesmo a umidade dos pós nos estádios 2 , 3 e 4 terem aumentado para as duas embalagens, a laminada conseguiu promover um teor de umidade para os três pós.

Figura 3. Valores médios da umidade do pó de manga 'Ataulfo' para a interação estádio de maturação com tipo de embalagem (A), estádio de maturação com período de armazenamento (B) e tipo de embalagem com período de armazenamento(C).
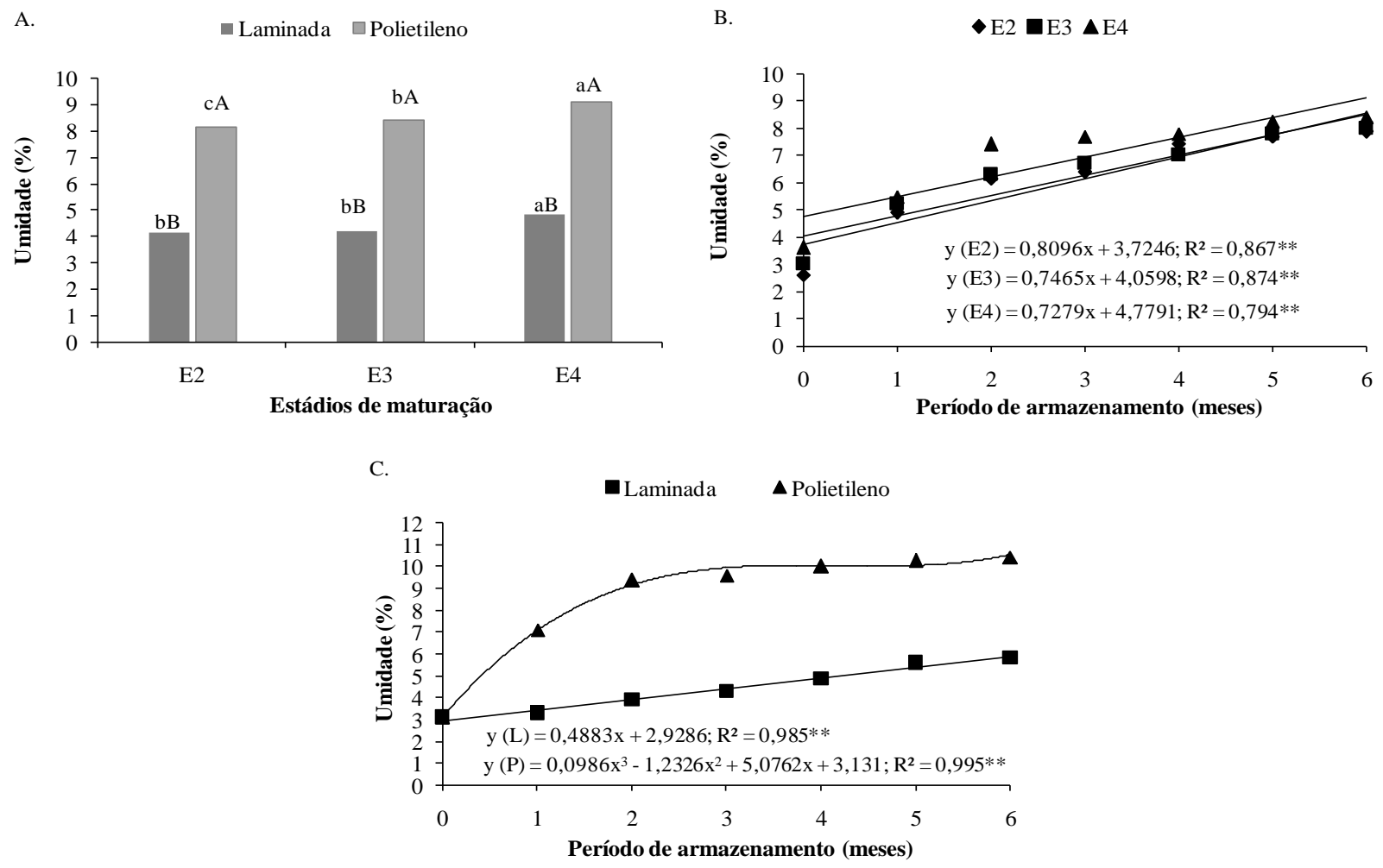

Fonte: Autores.

Na Figura 3.B durante todo o período de armazenamento independente dos estádios de maturação 2 , 3 e 4 o teor de umidade também foi aumentando com valores iniciais de 3, 3 e 4 respectivamente, e no final, tempo 6 , o teor de $8 \%$ para os três estádios.

As embalagens laminada e de polietileno na interação com o período de armazenamento (Figura 3.C), mostram que houve nos primeiros meses de armazenamento um aumento da umidade, sendo maior para a embalagem de polietileno (6 e $9 \%$ ) e menor ( 3 e $4 \%$ ) para a laminada.

Alexandre et al. (2014) estudaram o armazenamento de pitanga em pó em embalagem do tipo multifoliada, e constataram para o período de 60 dias, comportamento similar ao encontrado nessa pesquisa, isto é, tendência no aumento da 
umidade no decorrer dos intervalos estudados. Também ficou claro que após 30 dias de armazenamento houve diferença significativa entre as médias quando estas forem comparadas com o tempo 0.

Em estudo com o do pó de figo- da- índia obtido pelo método de camada de espuma e armazenado em embalagem laminada por um período de 100 dias, Lisbôa, Figueirêdo e Queiroz (2012), observaram que todas amostras absorveram água durante todo período estudado.

O teor de umidade da polpa de manga em pó armazenada em embalagem laminada encontrado no trabalho de Costa (2017), teve uma variação de 3,52 $\pm 0,31 \%$ a $4,85 \pm 0,11 \%$ durante o armazenamento. Desta forma os dados do presente trabalho mostram que a embalagem de polietileno ofereceu pouca barreira ao vapor de água, tendo a embalagem laminada ofertado uma maior barreira para o aumento do teor de umidade.

A vitamina C (ácido ascórbico) é um antioxidante, natural sensível ao calor, e a sua degradação na presença de luz e oxigênio ocorrem devido a uma não adequada condição de armazenamento (Oliveira et al., 2013).

Mesmo diante da redução do teor de ácido ascórbico nos três pós de manga a embalagem laminada durante os seis meses de armazenamento dos pós conseguiu concentrar mais o teor de ácido ascórbico com variação de 30 no tempo 0 a 28 mg. $100 \mathrm{~g}^{-1}$ para o último mês, Figura 4. A embalagem de polietileno durante o período de armazenamento apresentou uma maior queda no teor de ácido ascórbico saindo de $30 \mathrm{mg} .100 \mathrm{~g}^{-1}$ no tempo 0 para menos de $20 \mathrm{mg} 100 \mathrm{~g}^{-1}$ no último mês, comprovando que para esta variável esta embalagem não se mostrou eficiente.

Figura 4. Valores médios da vitamina C (ácido ascórbico) do pó de manga 'Ataulfo' para a interação estádio de maturação com tipo de embalagem (A), estádio de maturação com período de armazenamento (B) e tipo de embalagem com período de armazenamento(C).
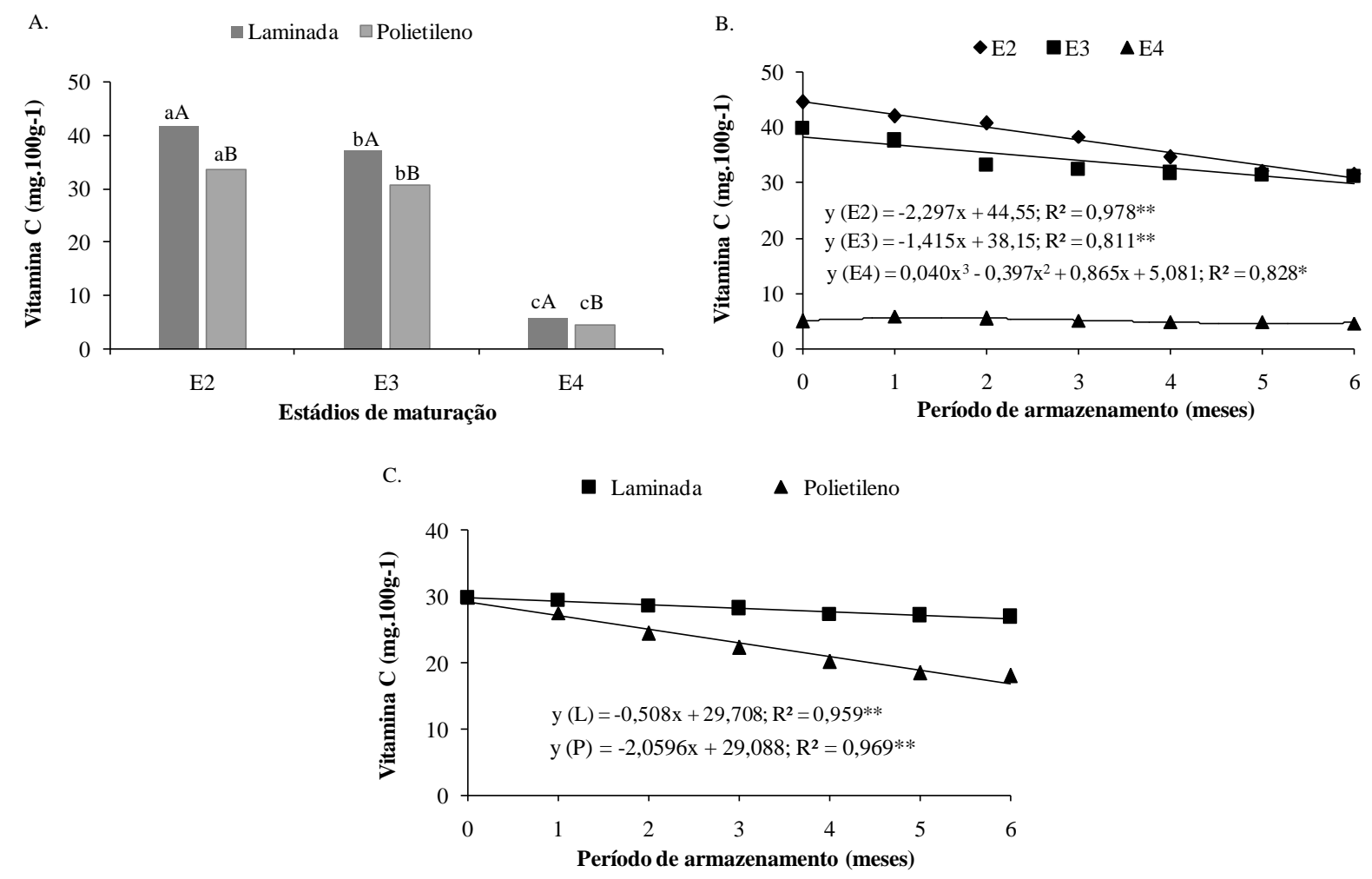

Fonte: Autores. 
Sousa et al. (2016) encontraram resultados similares em pesquisas realizadas com polpa de caju em pó armazenadas em embalagens laminadas e de polietileno, onde a embalagem de polietileno apresentou acentuada redução do ácido ascórbico a partir de 45 dias de armazenamento até o fim do experimento.

Costa (2017) com pó de manga desidratado apresentou valores de ácido ascórbico no tempo 0, valores que variaram entre 26,39 a 37,51 mg $100 \mathrm{~g}^{-1}$. Ao final dos 90 dias de estudo da estabilidade o valor máximo não ultrapassou 23,08 mg $100 \mathrm{~g}$ 1; mostrando que houve a redução do teor de ácido ascórbico, resultados estes similares aos encontrados no presente estudo.

Na Figura 5.A pode-se observar para ATT quer dentro quer entre os estádios de maturação redução estatística da acidez total titulável, com melhor conservação dos pós da manga 'Ataulfo' liofilizado para a embalagem laminada. Já a figura 5.B mostra uma pequena redução do teor de acidez do pó E2 de mais ou menos 0,5, nos 30 primeiros dias, mantendo-se até o final do período de armazenamento com um teor de 12\% de acidez. No entanto para o pó E3 houve um aumento no teor de acidez do tempo 0 ao tempo1, apresentando um valor de mais ou menos 8,7\% permanecendo constante até o tempo 5 , vindo aumentar $\pm 0,2 \%$ no tempo 6 . O pó $\mathrm{E} 4$ de acordo com esta mesma figura presentou uma linearidade quanto ao teor de acidez durante todo o período de seu armazenamento.

Figura 5. Valores médios da acidez total titulável do pó de manga ‘Ataulfo' para a interação estádio de maturação com tipo de embalagem (A), estádio de maturação com período de armazenamento (B).
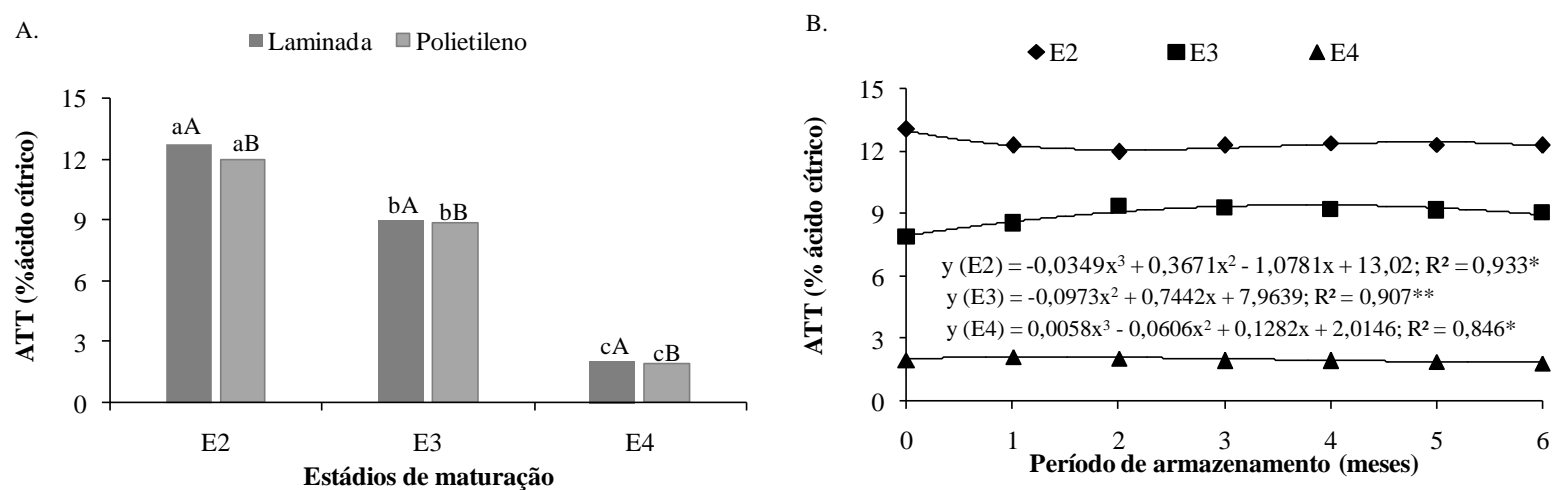

Fonte: Autores.

Na Tabela 2 estão expressos os resultados das médias da acidez dos pós sob a influência da interação entre as embalagens e o tempo de armazenamento, onde se observa igualdade estatística no tempo 0 para as embalagens. No entanto, no decorrer do experimento houve diferença significativa entre as embalagens laminada e polietileno do tempo 1 (30 dias) 7,85 e 7,46 ao tempo 6 (180 dias) 8,04 e 7,40 respectivamente, para o teor de acidez titulável. Analisando as médias para a mesma embalagem durante o período de armazenamento, a ATT da embalagem laminada aumentou nos primeiros 30 dias sendo mantida até o tempo 6. Quanto a embalagem de polietileno a acidez total titulavel permaneceu igual estatisticamente do tempo 0 ao 5 , vindo a diferenciar, com redução para menos, no tempo 6.

Tabela 2. Influência da interação embalagens com o tempo de armazenamento na acidez total titulável do pó de manga ‘Ataulfo' nos estádios E2, E3 e E4.

\begin{tabular}{ccccccccc}
\hline \multirow{2}{*}{ Embalagens } & \multicolumn{7}{c}{ Período de Armazenamento } \\
\cline { 2 - 6 } & $\mathbf{0}$ & $\mathbf{1}$ & $\mathbf{2}$ & $\mathbf{3}$ & $\mathbf{4}$ & $\mathbf{5}$ & $\mathbf{6}$ \\
\cline { 4 - 7 } Laminada & $7,61 \mathrm{aB}$ & $7,85 \mathrm{aA}$ & $8,07 \mathrm{aA}$ & $8,10 \mathrm{aA}$ & $8,08 \mathrm{aA}$ & $8,04 \mathrm{aA}$ & $8,04 \mathrm{aA}$ \\
Polietileno & $7,61 \mathrm{aB}$ & $7,46 \mathrm{bB}$ & $7,53 \mathrm{bB}$ & $7,56 \mathrm{bB}$ & $7,63 \mathrm{bB}$ & $7,55 \mathrm{bB}$ & $7,40 \mathrm{bC}$ \\
\hline
\end{tabular}

Médias seguidas de mesma letra minúscula na linha e maiúscula na coluna não diferem estatisticamente pelo teste de Tukey a $5 \%$ de probabilidade. Fonte: Autores. 
A acidez natural de uma polpa de fruta em pó tem sua importância quanto as suas propriedades organolépticas, evitando a ação de processos de fermentação, mas principalmente por estar variável ser de grande interesse para as indústrias alimentícias (Xie et al., 2011).

Os resultados encontrados por Galdino et al., (2016) com figo da índia em pó obtido por atomização, apresentou pequenas variações ao longo do tempo de armazenamento, mas sem diferenças significativas entre a acidez inicial e ao final dos 40 dias de armazenamento. Lisbôa, Figueirêdo e Queiroz (2012), que também trabalhou com a secagem de figo da índia em camada de espuma também observou uma discreta redução da acidez, em torno de $\pm 5 \%$, ao final dos 80 dias de armazenamento. Resultados estes também observados nesse experimento.

A Figura 6.A ilustra a influência da interação estádio de maturação com o tipo de embalagem, onde se observa diferença estatística entre os estádios 2, 3 e 4 para a embalagem laminada cujos pós apresentaram teor de sólidos solúveis de 20, 26 e 71 Brix $^{\circ}$ respectivamente. O mesmo aconteceu com a embalagem de polietileno para os pós dos estádios 2, 3 e 4.

Figura 6. Valores médios dos sólidos solúveis do pó de manga 'Ataulfo' para a interação estádio de maturação com tipo de embalagem (A), tipo de embalagem com período de armazenamento (B).
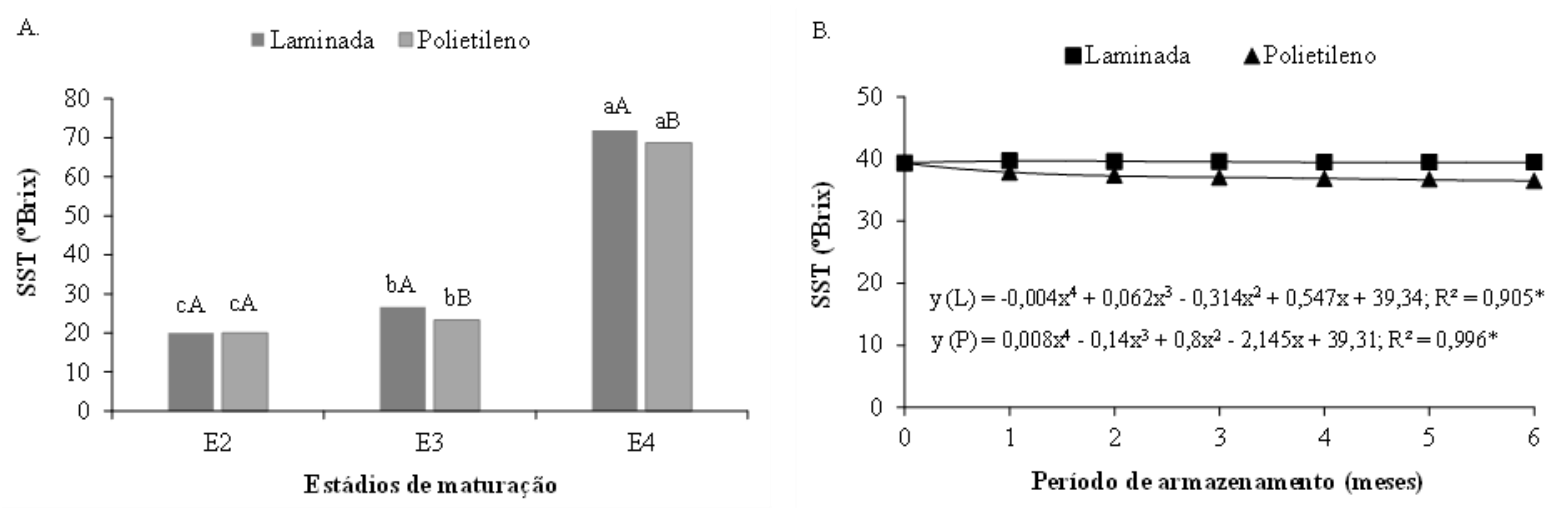

Fonte: Autores.

Em análise a Figura 6.A e a 6.B, independente da interação embalagem com estádio de maturação e com o período de armazenamento, a embalagem laminada apresentou um maior teor de sólidos solúveis com cerca de $2^{\circ}$ Brix de diferença a mais que a embalagem de polietileno. Sendo está embalagem adequada para o armazenamento de material em pó.

Loureiro et al. (2013) estudando o armazenamento de buriti em pó desidratado em estufa a $50^{\circ} \mathrm{C}$ e acondicionado em embalagens de polietileno e laminadas por um período de 90 dias encontraram para as respectivas embalagens valores iniciais de 10,27 e 9,93 e finais de 10,27 e 9,83 Brix $^{\circ}$, deixando claro que a embalagem laminada preservou melhor o teor de sólidos solúveis.

Costa (2017) observou em seu trabalho com pó de polpa de manga desidratado em spray-dryer e armazenadas em quatro embalagens, que houve uma pequena redução de no ${ }^{\circ}$ Brix do pó de manga. Quanto que para a embalagem laminada observou-se uma elevação do Brix $^{\circ}$ permanecendo estes valores estáveis até o final do armazenamento.

Moreira et al. (2011) estudando a estabilidade de polpa de cupuaçu em pó, desidratado em estufa a $60^{\circ} \mathrm{C}$, armazenados em embalagens de polietileno de baixa densidade por 90 dias, observaram que os teores de sólidos solúveis diminuíram linearmente durante os tempos iniciais (0) e finais (90) de 29,08 e 28,09; 30,11 e 29,23; 30,11 e 29,23 respectivamente nas polpas desidratadas.

Na Tabela 3 abaixo estão expressos os valores da influência da interação entre os estádios de maturação dos pós de manga ‘Ataulfo' com o seu período de armazenamento para a variável $\mathrm{pH}$. 
Tabela 3. Influência da interação estádios de maturação dos pós com o tempo de armazenamento no pH do pó de manga 'Ataulfo' nos estádios E2, E3 e E4.

\begin{tabular}{|c|c|c|c|c|c|c|c|}
\hline \multirow{2}{*}{ Estádios } & \multicolumn{7}{|c|}{ Período de Armazenamento } \\
\hline & $\mathbf{0}$ & 1 & 2 & 3 & 4 & 5 & 6 \\
\hline E2 & $3,13 \mathrm{cC}$ & $3,01 \mathrm{cC}$ & $3,06 \mathrm{cC}$ & $3,07 \mathrm{cC}$ & $2,94 \mathrm{cC}$ & $3,09 \mathrm{cC}$ & $3,10 \mathrm{cC}$ \\
\hline $\mathbf{E 3}$ & $3,39 \mathrm{bB}$ & $3,17 \mathrm{bB}$ & $3,26 \mathrm{bB}$ & $3,16 \mathrm{bB}$ & $3,28 \mathrm{bB}$ & $3,30 \mathrm{bB}$ & $3,31 \mathrm{bB}$ \\
\hline E4 & $4,69 \mathrm{aA}$ & $4,45 \mathrm{aA}$ & $4,66 \mathrm{aA}$ & $4,48 \mathrm{aA}$ & $4,54 \mathrm{aA}$ & $4,55 \mathrm{aA}$ & $4,56 \mathrm{aA}$ \\
\hline
\end{tabular}

Médias seguidas de mesma letra minúscula na linha e maiúscula na coluna não diferem estatisticamente pelo teste de Tukey a 5\% de probabilidade. Fonte: Autores.

$\mathrm{O}$ pH inicial dos pós de cada estádio de maturação permaneceu o mesmo estatisticamente durante todo o tempo de armazenamento. Enquanto dentro de cada tempo de armazenamento, este aumentou com o estádio de maturação da manga 'Ataulfo' (E4>E3>E2) Moura (2010) em seu estudo com polpa de acerola atomizada armazenada em embalagem laminada durante 360 dias, mostrou que não houve diferença significativa de $\mathrm{pH}$ durante todo o período de armazenamento. Resultado este similar aos encontrados neste trabalho.

Mediante os resultados da Tabela 4 tem-se igualdade estatística para a embalagem laminada em todos os tempos de armazenamento, não ocorrendo o mesmo com a embalagem de polietileno que diferenciou com um pH inferior nos tempos 2,3 e 4 dos anteriores e posteriores. Com relação ao pH das embalagens dentro de cada tempo, tem-se igualdade estatística do tempo inicial (0) com os tempos 4, 5 e 6 . Em resumo observa-se para a embalagem laminada o mesmo pH durante o armazenamento, ocorrendo o contrário com a embalagem de polietileno, que durante o armazenamento o pH nos tempos 2 , 3 e 4 diminuíram e aumentaram nos tempos 5 e 6 que se igualaram aos tempos 0 e 1 . Este aumento do pH nos últimos dias de armazenamento dos pós pode ser um indicativo de que as amostras estavam em processo de decomposição por hidrólise ou oxidação ou fermentação os quais podem alterar a concentração de íons de hidrogênio e a sua acidez (Alexandre et al., 2014).

Tabela 4. Interação embalagens com tempo de armazenamento do pH do pó de manga ‘Ataulfo' nos estádios de maturação E2, E3 e E4.

\begin{tabular}{ccccccccc}
\hline \multirow{2}{*}{ Embalagens } & \multicolumn{7}{c}{ Período de Armazenamento } \\
\cline { 2 - 7 } & $\mathbf{0}$ & $\mathbf{1}$ & $\mathbf{2}$ & $\mathbf{3}$ & $\mathbf{4}$ & $\mathbf{5}$ & $\mathbf{6}$ \\
\cline { 4 - 7 } Laminada & $3,73 \mathrm{aA}$ & $3,53 \mathrm{bA}$ & $3,62 \mathrm{bA}$ & $3,55 \mathrm{bA}$ & $3,59 \mathrm{aA}$ & $3,65 \mathrm{aA}$ & $3,66 \mathrm{aA}$ \\
Polietileno & $3,73 \mathrm{aA}$ & $3,70 \mathrm{aA}$ & $3,56 \mathrm{aC}$ & $3,59 \mathrm{aC}$ & $3,59 \mathrm{aC}$ & $3,64 \mathrm{aB}$ & $3,65 \mathrm{aB}$ \\
\hline
\end{tabular}

Médias seguidas de mesma letra minúscula na coluna e maiúscula na linha não diferem estatisticamente pelo teste de Tukey a $5 \%$ de probabilidade. Fonte: Autores.

Alexandre et al. (2014) com o armazenamento de pitanga em pó constataram um aumento significativo do pH nos últimos 15 dias de armazenamento sendo está uma indicação de que a amostra estava em processo de decomposição por hidrólise ou oxidação ou fermentação, alterando assim a concentração dos íons de hidrogênio e, consequentemente, sua acidez 
Para tanto, observando os dados apresentados neste trabalho mesmo que alguns resultados tenham apresentado algumas alterações significativas ao se tratar do $\mathrm{pH}$ dos pós alimentícios, este se manteve dentro da faixa que assegura a prevenção da perda de suas propriedades por deterioração (Oliveira, Afonso \& Costa, 2011)

Assim, evidencia-se que o emprego de qualquer uma das embalagens (laminada ou polietileno) no armazenamento de polpa de manga 'Ataulfo' em pó liofilizada até o tempo 6 meses (180dias) não acarretariam em resultados discrepantes para $\mathrm{pH}$.

A escolha de um produto alimentício por parte do consumidor depende primeiramente de seu aspecto visual, a cor e a aparência são atributos que influenciam na aceitação e ou rejeição de um determinado alimento (Bobbio \& Bobbio, 2001)

Através da Figura 7 observa-se o comportamento da luminosidade da manga Ataulfo com os estádios de maturação para as embalagens dos pós liofilizados desta manga. A embalagem laminada apresentou uma luminosidade acima de 75 para os pós nos estádios 2 e 3, e de 65 para o estádio 4. Quanto a embalagem de polietileno também não se observou diferença significativa para os pós dos estádios 2 e 3 que também apresentaram uma luminosidade em torno de 75 e 59 para o pó do estádio 4.

Figura 7. Valores médios da Luminosidade do pó de manga 'Ataulfo' para a da interação estádio de maturação com tipo de embalagem. Médias seguidas da mesma letra minúscula, entre os estádios maturação para um mesmo tipo de embalagem e maiúsculas para o mesmo estádio de maturação utilizando as diferentes embalagens, não diferem estatisticamente pelo teste de Tukey a $5 \%$ de probabilidade.

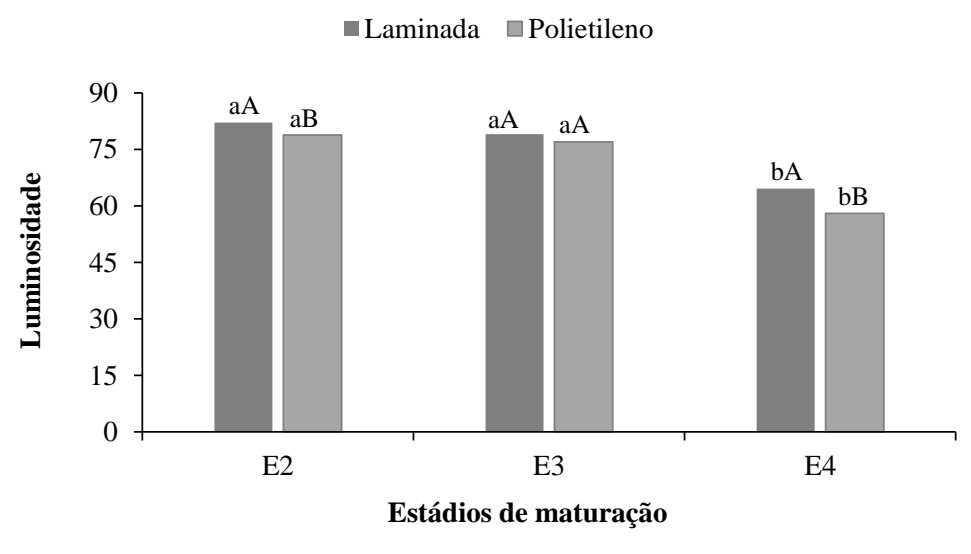

Fonte: Autores.

A interação entre um mesmo estádio de maturação com os dois tipos de embalagens, mostrados na figura acima, expressam igualdade estatística para as embalagens laminada e de polietileno com pó liofilizado da manga Ataulfo obtido no estádio 3 de maturação e, diferença estatística quanto ao pó obtido nos estádios 2 e 4.

Loureiro et al., (2013) ao estudar o buriti em pó, desidratado em estufa sob diferentes temperaturas e armazenados em embalagens de polietileno e laminadas por um período de 90 dias, constataram que os valores de L* das amostras obtidas a partir das três temperaturas de secagem não foram influenciados estatisticamente pelo tipo de embalagem que foram utilizadas, nem pelo período de armazenamento.

Na Tabela 5 estão expressos os resultados da interação entre os estádios de maturação dos pós da manga 'Ataulfo' com o período de armazenamento. 
Tabela 5. Interação embalagens com tempo de armazenamento da luminosidade do pó de manga 'Ataulfo' nos estádios de maturação E2, E3 e E4.

\begin{tabular}{cccccccc}
\hline \multirow{2}{*}{ Estádios } & \multicolumn{7}{c}{ Período de Armazenamento } \\
\cline { 2 - 8 } & $\mathbf{0}$ & $\mathbf{1}$ & $\mathbf{2}$ & $\mathbf{3}$ & $\mathbf{4}$ & $\mathbf{5}$ & $\mathbf{6}$ \\
\hline E2 & $71,53 \mathrm{aA}$ & $81,83 \mathrm{aA}$ & $83,31 \mathrm{aA}$ & $84,02 \mathrm{aA}$ & $83,57 \mathrm{aA}$ & $81,33 \mathrm{aA}$ & $77,70 \mathrm{aA}$ \\
E3 & $70,37 \mathrm{aA}$ & $81,44 \mathrm{aA}$ & $81,00 \mathrm{aA}$ & $79,79 \mathrm{aA}$ & $80,75 \mathrm{aA}$ & $80,65 \mathrm{aA}$ & $77,05 \mathrm{aA}$ \\
E4 & $65,37 \mathrm{bB}$ & $62,24 \mathrm{bB}$ & $60,13 \mathrm{bB}$ & $60,48 \mathrm{bB}$ & $60,41 \mathrm{bB}$ & $55,87 \mathrm{bB}$ & $64,49 \mathrm{bB}$ \\
\hline
\end{tabular}

Médias seguidas de mesma letra minúscula na coluna e maiúscula na linha não diferem estatisticamente pelo teste de Tukey a $5 \%$ de probabilidade. Fonte: Autores.

A luminosidade dos pós nos estádios 2 e 3 não diferiram estatisticamente durante todo o período de armazenamento e, foram superiores ao do estádio E4. Estes resultados encontram apoio aos obtidos por Costa et al., (2013) para a polpa de maracujá atomizada, acondicionada em embalagem laminada, e que durante 90 dias de armazenamento a luminosidade se manteve a mesma estatisticamente que estatisticamente se igualou, com valor inferior da luminosidade, em todos os tempos em que os pós permaneceram armazenados. Esta ocorrência deu-se dentro dos estádios de maturação (E2 e E3) em um mesmo tempo e entre os tempos para o mesmo estádio de maturação.

A menor luminosidade do pó do estádio 4, deve-se provavelmente, ao escurecimento da polpa e da redução do conteúdo de água, devido a fatores como o estádio de maturação dos frutos, em virtude da temperatura utilizada no processo de liofilização sendo sendo esse um fator capaz de promover alterações na cor original da amostra Ferreira et al., (2014). Por isso a menor reflexão da luz incidente em E4.

Quanto aos valores de $\mathrm{a}^{*}$, conforme se observa na Figura 8.A, o aumento foi mais acentuado para o pó no estádio 4 tanto para a embalagem laminada quanto para a de polietileno que indicam uma maior redução da cor verde, seguidos do pó no estádio 3 e 2 para esta mesma característica.

Figura 8. Valores médios da Cor a* do pó de Manga 'Ataulfo' para a interação estádio de maturação com tipo de embalagem (A) e estádio de maturação com período de armazenamento (B).
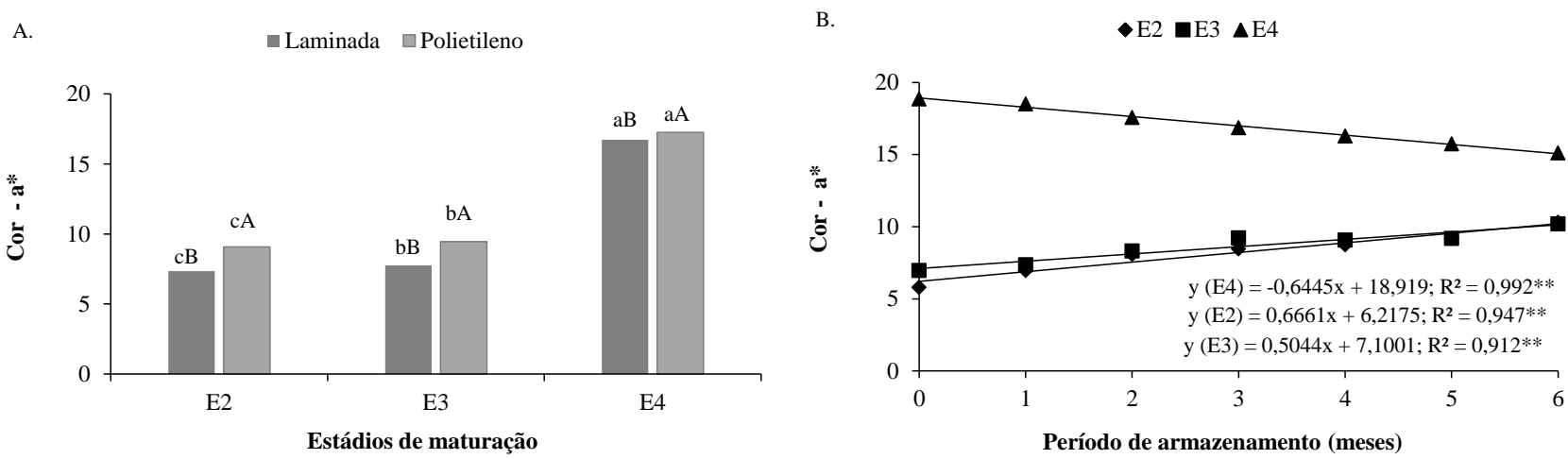

Fonte: Autores.

A influência da interação entre os estádios e período de armazenamento, Figura 8.B está no fato de o valor de a* para o pó no estádio 4 ter sido decrescente com valor inicial no tempo 0 de 19 e final de 15,5 . Nos estádios 2 e 3 houve aumento gradativo com valores iniciais de 5 e 6 e finais entorno de 9 respectivamente.

Tabela 6. Médias da interação embalagens com o tempo de armazenamento para a Cor- a* do pó de manga 'Ataulfo' nos estádios E2, E3 e E4 de maturação. 
Para a interação embalagem com tempo de armazenamento Tabela 6, têm-se a exceção do tempo 0, a embalagem de polietileno armazenou o pó da manga Ataulfo liofilizado com valores maiores para todos os tempos do armazenamento; tendo está embalagem mantido igualdade estatística para o armazenamento do referido pó entre os tempos em que este permaneceu armazenado. Enquanto que para a embalagem laminada no tempo 1 e 5 os valores da cor foram iguais, porém estatisticamente inferiores aos registrado nos demais tempo que também não diferiram estatisticamente.

Tabela 6. Médias da interação embalagens com o tempo de armazenamento para a Cor- a* do pó de manga 'Ataulfo' nos estádios E2, E3 e E4 de maturação.

\begin{tabular}{cccccccc}
\hline Embalagens & \multicolumn{7}{c}{ Período de Armazenamento } \\
\cline { 2 - 7 } & $\mathbf{0}$ & $\mathbf{1}$ & $\mathbf{2}$ & $\mathbf{3}$ & $\mathbf{4}$ & $\mathbf{5}$ & $\mathbf{6}$ \\
\cline { 4 - 8 } Laminada & $10,53 \mathrm{aA}$ & $10,45 \mathrm{bB}$ & $10,65 \mathrm{bA}$ & $10,64 \mathrm{bA}$ & $10,58 \mathrm{bA}$ & $10,37 \mathrm{bB}$ & $11,00 \mathrm{bA}$ \\
Polietileno & $10,53 \mathrm{aA}$ & $11,42 \mathrm{aA}$ & $11,97 \mathrm{aA}$ & $12,37 \mathrm{aA}$ & $12,13 \mathrm{aA}$ & $12,30 \mathrm{aA}$ & $12,73 \mathrm{aA}$ \\
\hline
\end{tabular}

Médias seguidas de mesma letra minúscula na coluna e maiúscula na linha não diferem estatisticamente pelo teste de Tukey a 5\% de probabilidade. Fonte: Autores.

Ribeiro (2014) em seus estudos com armazenamento de polpa de acerola liofilizada apresentaram resultados com discreto aumento nos valores do parâmetro a* durante os 90 dias de estudo, tendo maiores valores para a embalagem plástica. Lisbôa, Figueirêdo e Queiroz (2012), obtiveram também aumento da intensidade do vermelho no armazenamento em embalagem laminada com figo da índia em pó, e estabilidade ao final de 80 dias do armazenamento. Já Alexandre et al. (2014) observaram comportamento inverso ao trabalharem com pitanga em pó acondicionada em embalagem plástica, em que, apresentou um decréscimo de intensidade vermelho de $\pm 30 \%$ no final de 60 dias de armazenamento.

Galdino et al. (2016) em seu experimento com pó de fígo-da-índia, desidratado em spray-dryer obtiveram redução da coordenada $\mathrm{a}^{*}$ com $35 \%$ de maltodextrina, armazenado em embalagens laminadas, a uma temperatura de $25^{\circ} \mathrm{C}$ e período de 40 dias. Já Oliveira et al. (2015) no pó do fruto de mandacaru, desidratado em spray dryer com 10\% de maltodextrina DE (10), armazenado em embalagens laminadas, por um período de 50 dias, relataram também redução da cor a*.

Os resultados do presente estudo deixam claro que a coordenada $\mathrm{a}^{*}$ durante o experimento apresentou valores maiores para os pós armazenados nas embalagens de polietileno até o final do experimento.

Figura 9. Valores médios da Cor b* do pó da manga 'Ataulfo' para a interação estádio de maturação com tipo de embalagem (A), estádio de maturação com período de armazenamento (B).

A.

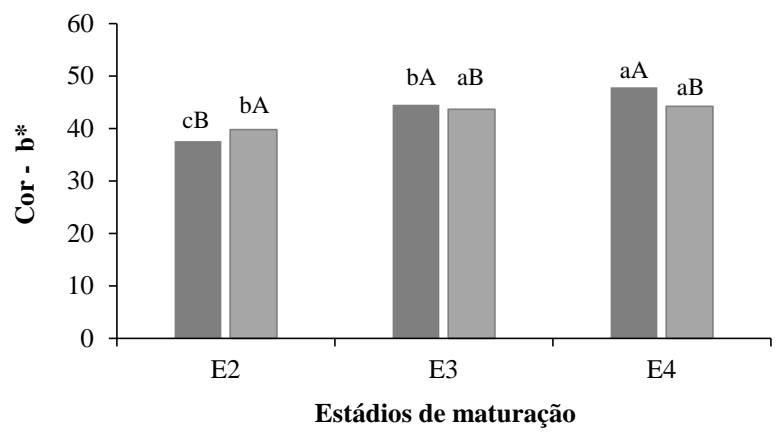

B.

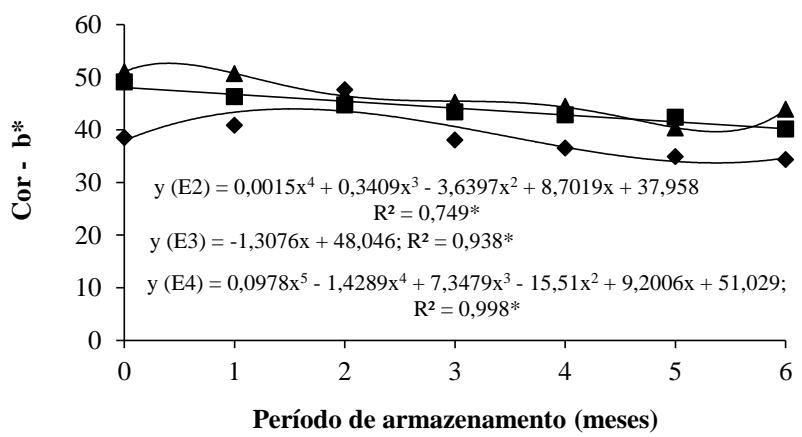

Fonte: Autores. 
Ainda em análise a esta figura tem-se, que o pó no estádio 4 apresentou maior valor da cor b* para a embalagem laminada, entono de 48, valor este maior quando comparado com os pós nos estádios 2 e 3 que foi de 38 e 45 , respectivamente. A embalagem de polietileno dos pós nos estádios 3 e 4 não diferiram estatisticamente entre si apresentando valor para a cor de b* de 44. Para o pó no estádio 2 esse valor foi menor que 40.

Quanto a interação entre as duas embalagens para um mesmo estádio de maturação, houve diferença significativa entre as embalagens laminadas e de polietileno para os pós nos três estádios. A média da embalagem laminada para o estádio 2 apresentou um valor da cor b* menor que a embalagem de polietileno de 37 e 40 respectivamente. Nos pós dos estádios 3 e 4 , a embalagem laminada apresentou teor da cor $b *$ maior que a embalagem de polietileno.

Com relação a Figura 9.B verifica-se que durante o período de armazenamento o pó do estádio 2 no tempo 0 ao tempo 2 apresentou aumento da cor $\mathrm{b}^{*}(45)$, no entanto no último período, tempo 6 , houve uma redução da cor $\mathrm{b}^{*}$ atingindo os 37 . No estádio 3 durante todo o período de armazenamento houve redução da cor b* com valor de 48 inicial e 41 no final do experimento. Quanto ao pó no estádio 4 houveram variações com a redução, nos tempos 1 ao 5 e o aumento, no tempo 6, da cor b* durante todo o período de armazenamento.

Galdino et al., (2016) observaram no pó de fígo-da-índia desidratado em spray-dryer, adicionados de maltodextrina e armazenados em embalagem laminada, comportamento similar ao desta pesquisa, redução na coordenada b* . Alexandre et al., (2014) no armazenamento de pitanga em pó em embalagem multifolhada com armazenamento de 60 dias, também verificaram redução no valor para a cor b*, da tonalidade do amarela para o pó de pitanga. Divergindo com os resultados encontrados nesse experimento, Oliveira et al. (2015) estudando a estabilidade do pó de mandacaru armazenado em embalagem laminada por um período de 50 dias relataram aumento para a cor b* nos pós adicionados de maltodextrina.

Estes resultados só confirmam o que já vem sendo analisado durante todo o experimento que, independente do estado em que se encontram a matéria prima, seja na forma in natura ou liofilizada, as reações e mudanças sejam elas de cor, de doçura, de textura dentre outras, continuam acontecendo mesmo sendo armazenadas em embalagens apropriadas.

\section{Conclusão}

Os resultados permitiram examinar diferenças físicas e físico-químicas dos pós de polpa de manga 'Ataulfo' em três diferentes estádios de maturação;

O processo de liofilização da polpa integral da manga ‘Ataulfo' é eficiente e eficaz na desidratação dessa fruta;

Os pós liofilizados da manga 'Ataulfo' se armazenaram bem durante o período de armazenamento nos dois tipos de embalagens (laminada e polietileno) estudadas, com destaque para a laminada que preservou com eficácia as propriedades fisico-químicas: atividade de água, umidade, cor $\left(\mathrm{L}^{*}, \mathrm{a}^{*} \mathrm{e} \mathrm{b}^{*}\right)$ sólidos solúveis, $\mathrm{pH}$, vitamina $\mathrm{C}$ e acidez total titulável, mostrando-se ser mais eficiente.

Os pós da polpa da manga 'Ataulfo' nos estádios 2, 3 e 4 de maturação podem ser utilizados na elaboração de diversos produtos da indústria alimentícia, mediante o teste de aceitação por parte do consumidor, por ser um produto integral;

Esse estudo tende a valorizar uma variedade de manga ainda pouco estudada e utilizada no Brasil, sendo este trabalho relevante para caracterização e uso de novas formas da manga 'Ataulfo', podendo ser referência para outras pesquisas desenvolvidas com este mesmo fruto.

\section{Agradecimentos}

Os autores agradecem à Coordenação de Aperfeiçoamento de Pessoal de Nível Superior (CAPES) pela bolsa de Doutorado concedida. 


\section{Referências}

Alexandre, H. V., Figueirêdo, R. M. F., Queiroz, A. J. M., \& Oliveira, E. N. A. (2014). Armazenamento de pitanga em pó. Comunicata Scientiae, 5(1), 83-91. AOAC (1980). Official methods of analysis of the association of Official Analystical Chemists. (3a ed.), 359-373.

Benassi, M. T. \& Antunes, A. J. A. (1988). comparison of metaphosphoric and oxalic acids as extractants solutions for the determination of vitamin C in selected vegetables. Brazilian Archives of Biology and Technology, 31(4), 507-513.

Blancas-benitez, F. J., De Jesús Avena-bustillos, R., \& Montalvo-gonzález, E. et al. (2015). Addition of dried 'Ataulfo'mango (Mangifera indica L.) byproducts as a source of dietary fiber and polyphenols in starch molded mango snacks Journal of Functional Foods, 52(7393), 65-73.

Bobbio, P. A., \& Bobbio, F. O. (2001) Química do Processamento de Alimentos. Livraria Varela, (3a ed.), 5 - 6.

Costa, J. N., Figueiredo, R. W., Sousa, P. H. M., Costa, M. L. G.; Constant, P. B. L., \& Soares, D. J. (2013). Study of the stability of passion fruit powder (Passiflora edullis f. flavicarpa) from organic farming. Semina: Ciências Agrárias, 34(2), 705-716.

Costa, L. O. (2017). Obtenção de polpa de manga em pó pelo processo de liofilização. 2017. 119f. Dissertação (Mestrado em Ciência e Tecnologia de Alimentos), Universidade Federal do Ceará- CE.

De Ancos, B., Sánchez-moreno, C., \& Zacarías, L., et al. (2018) Effects of two different drying methods (freeze-drying and hot air-drying) on the phenolic and carotenoid profile of 'Ataulfo' mango by-products. Food Measure, 12, 2145-2157.

Ferreira, A. P. R. et al. (2014). Caracterização de polpa de cajá em pó obtida pelo método de secagem em leito de jorro. In: XX Congresso Brasileiro de Engenharia Química - COBEQ. Florianópolis - SC, 19 a 22 de out.

Galdino, P. O., Figueirêdo, R. M., Queiroz, A. J. D. M.; Galdino, P. O., \& Fernandes, T. K. D. S. (2016). Stability of cactus-pear powder during storage. Revista Brasileira de Engenharia Agrícola e Ambiental, 20(2), 169-173.

IAL. (2008). Instituto Adolfo Lutz. Métodos físico-químicos para análise de alimentos. (4a ed.), Instituto Adolfo Lutz, 1020.

IBGE. 2019. Instituto Brasileiro de Geografia e Estatística. Sistema IBGE de recuperação automática - SIDRA. http://www.sidra.ibge.gov.br/tabela/1613.

Jahurul, M. H. A., Zaidul, I. S. M., Ghafoor, K., Al-juhaimi, F. A., Nyam, K. L., Norulaini, N. A. N., Sahena, F., \& Mohd-oomar, A. K. (2015). Mango (Mangifera indica L.) by-products and their valuable components. Food Chemistry, 183, 173-180.

Lisbôa, C. G. C, Figueirêdo, R. M. F. \& Queiroz, A. J. M. (2012). Armazenamento de figo-daíndia em pó. Revista Brasileira de Engenharia Agrícola e Ambiental, 16(2), 216-221.

Loureiro, M. N., Figueirêdo, R. M. F., Queiroz, A. J. M., \& Oliveira, E. N. A. (2013). Armazenamento de buriti em pó: efeito embalagem nas características físicas e químicas. Bioscience Journal, Uberlândia, 29(5), 1092 - 1100.

Moreira, J. S. A., Souza, M. L., Araújo Neto, S. E., \& Silva, R. F. (2011). Estudo da estabilidade microbiológica e físico-química de polpa de cupuaçu desidratada em estufa. Revista Caatinga, Mossoró, 24(2), 26 - 32.

Moura, S. M. (2010). Estabilidade da acerola em pó oriunda de cultivo orgânico. 112 f. Dissertação [Mestrado em Ciência e Tecnologia de Alimentos] Centro de Ciências Agrárias, Universidade Federal do Ceará, Fortaleza, 2010.

Ochoa-martínez, C. I., Quintero, P. T., Ayala, A. A., \& Ortiz, M. J. (2012). Drying characteristics of mango slices using the Refractance Window ${ }^{\mathrm{TM}}$ technique. Journal of Food Engineering, v.109, p. 69-75.

Oliveira, V. S., Afonso, M. R. A., \& Costa, J. M. C. (2013). Caracterização físico-química e comportamento higroscópico de sapoti liofilizado. Revista Ciência Agronômica, 42(2), 342-348.

Oliveira, M. I. S., Tonon, R. V., Nogueira, R. I., \& Cabral, L. M. C. (2013). Estabilidade da polpa de morango atomizada utilizando diferentes agentes carreadores. Food Technology, 16(4), 310-318.

Oliveira, A. S. et al. (2015). Estabilidade da polpa do Cereus jamacaru em pó durante o armazenamento. Revista Brasileira de Engenharia Agrícola e Ambiental, 19(2), $147-153$.

Pereira, A. S., Shitsuka, D. M., Pereira, F. J., \& Shitsuka, R. (2018). Metodologia da pesquisa científica. UFSM, https://repositorio.ufsm.br/bitstr eam/handle/1/15824/Lic_Computacao_Metodologia- Pesquisa-Cientifica.pdf?sequence=1

Quirós-sauceda, A. E., Sañudo-barajas, J. A., Vélez-de La Rocha, R., et al. (2019). Effects of ripening on the in vitro antioxidant capacity and bioaccessibility of mango cv. 'Ataulfo' phenolics. J Food Sci Technol 56, 2073-2082.

Ribeiro, L. C. (2014). Produção de acerola em pó: métodos de secagem e avaliação da estabilidade. 124 f. Dissertação (Mestrado) - Centro de Ciências Agrárias, Universidade Federal do Ceará, Fortaleza.

Silva, F. de A. S., \& Azevedo, C. A. V. (2016). The Assistat Software Version 7.7 and its use in the analysis of experimental data. African Journal of Agricultural Research, 11(39), 3733-3740.

Silva, G. M. C., Silva, W. B.; Medeiros, D. B., Salvador, A. R., Cordeiro, M. H. M., Da Silva, N. M.; Santana, D. B., \& Mizobutsi, G. P. (2017). The chitosan affects severely the carbon metabolism in mango (Mangifera indica L. cv. Palmer) fruit during storage. Food Chemistry, 237, 372-378.

Singh, Z., Singh, R. K., Sane, V. A., \& Nath, P. (2013). Mango e postharvest biology and biotechnology. Critical Reviews in Plant Sciences, $32,217-236$. 
Research, Society and Development, v. 10, n. 3, e45710313596, 2021

(CC BY 4.0) | ISSN 2525-3409 | DOI: http://dx.doi.org/10.33448/rsd-v10i3.13596

Xie, L.; Ye, X.; Liu, D., \& Ying, Y. (2011). Prediction of titratable acidity, malic acid, and citric acid in bayberry fruit by near-infrared spectroscopy. Food Research International, 44, 2198-2204.

Zhao, J. H., Liu, F., Wen, X., Xiao, H. W., \& Ni, Y. Y. (2015). State diagram for freeze-dried mango: freezing curve, glass transition line and maximal-freezeconcentration condition. Journal of Food Engineering, 157, 49-56.

Zotarelli, M. F., Silva, V. M., Durigon, A., Hubinger, M. D., \& Laurindo, J. B. (2017). Production of mango powder by spray drying and cast-tape drying. Powder Technology, 305, 447-454. 